\title{
PHOTOGRAMMETRIC ASSESSMENT AND COMPARISON OF DJI PHANTOM 4 PRO AND PHANTOM 4 RTK SMALL UNMANNED AIRCRAFT SYSTEMS
}

\author{
M. V. Peppa*, J. Hall, J. Goodyear, J. P. Mills \\ School of Engineering, Newcastle University, Newcastle upon Tyne, UK - \\ (maria-valasia.peppa, j.s.hall1, james.goodyear, jon.mills) @ newcastle.ac.uk
}

\author{
Commission I/II, ICWG I/II
}

KEY WORDS: bundle adjustment, camera calibration, drones, photogrammetry, structure-from-motion, SUA, UAS, UAV

\begin{abstract}
:
Consumer-grade Unmanned Aircraft Systems (UAS), and particularly Small Unmanned Aircraft (SUA) weighing less than $20 \mathrm{~kg}$, have recently become very attractive for photogrammetric data acquisition across a wide range of applications. Compared to other more expensive remote-sensing technology, DJI Phantom series SUA provide a trade-off between cost, sensor quality, functionality and portability. Because of the significant interest in such systems, rigorous accuracy assessment of metric performance is crucial. This research investigates the capabilities of the Phantom 4 Pro (P4P) and the recently launched Phantom 4 RTK (P4RTK) SUA through both laboratory and in-situ assessments with multi-scale photogrammetric blocks. The study adopts self-calibrating bundle adjustments from conventional photogrammetry and from a Structure-from-Motion (SfM)-photogrammetric approach. Both systems deliver planimetric and vertical absolute accuracies of better than one and two pixels ground sampling distance, respectively, against independent check points. This can be achieved if the imaging network configuration includes a mixed range of nadir and oblique imagery and several ground control points are established as reference information. Ongoing analysis is investigating the strength of all bundle adjustment solutions. It is also evaluating the GNSS capabilities of the P4RTK SUA after post-processing raw observations of its trajectory. Findings from a comprehensive accuracy assessment can support non-experts in designing the preflight photogrammetric data acquisition plan and aid understanding of the performance of such popular off-the-shelf SUA.
\end{abstract}

\section{INTRODUCTION}

Consumer-grade Unmanned Aircraft Systems (UAS), and particularly Small Unmanned Aircraft (SUA) defined by the UK Civil Aviation Authority as weighing less than $20 \mathrm{~kg}$ (CAP $393,2019)$, in conjunction with off-the-shelf digital cameras have become common-place in providing detailed image capture for geoscientific applications over the last decade (Toth and Jóźków, 2016). Parallel to the emergence of SUA technology, the Structure-from-Motion (SfM) and Multi-ViewStereo (MVS) photogrammetric processing pipeline has become a common approach for delivering high spatio-temporal resolution digital elevation models (DEMs) from SUA-based imagery (James and Robson, 2014). Such an approach has been widely adopted into commercial software packages (e.g. Agisoft Metashape; Metashape (2018)) that usually offer automated photogrammetric routines designed for use by nonexperts. Therefore, comprehensive photogrammetric error assessments and a full understanding of the uncertainties associated with SfM-photogrammetric outputs are still crucial tasks, especially when emerging SUA systems are utilised for applications that may require $3 \mathrm{D}$ positional accuracy of centimetre-level or better.

A variety of consumer-grade SUA platforms exist and their suitability depends on the nature of the application and the environmental conditions. Whilst fixed-wing SUA are able to fly efficiently over large areas, rotary-wing SUA are easier to precisely manoeuvre, take off and land, especially when operating in challenging environments such as water, forests and steep rugged slopes. Recent studies have noted that there has been a significant reduction in purchase costs of commercial rotary-wing SUA fitted with consumer-grade instrumentation since 2010 (e.g. Woodget et al. (2015); Carbonneau and Dietrich (2017); Hese and Behrendt (2017)). Over the last two years, the rotary-wing DJI Phantom series (DJI, 2019) SUA have become increasingly attractive across a wide range of research applications such as: coral reef morphology over shallow waters (Casella et al., 2017); mapping and monitoring of glacier-related geomorphological structures (Ewertowski et al., 2019); crop canopy height monitoring (Malambo et al., 2018); 3D modelling of cultural heritage buildings (Chiabrando and Losè, 2017); and forest tree crown monitoring (Hese and Behrendt, 2017).

The aforementioned case studies demonstrate a growing interest in utilising DJI Phantom series SUA for photogrammetric operations as they provide a trade-off between cost, sensor quality, functionality and portability in comparison to other more expensive fixed-wing SUA or terrestrial laser scanning (TLS) technology (Hese and Behrendt, 2017; Ewertowski et al., 2019). Moreover, significant improvements in Phantom 4 Pro instrumentation are reported in comparison to its former model (Chiabrando and Losè, 2017).

\footnotetext{
* Corresponding author
} 
A number of recent studies have focused on eliminating the labour intensive and costly task of physically establishing GCPs, either through innovative methodologies (e.g. Grayson et al. (2018); Peppa et al. (2018)) and/or through the use of SUA platforms augmented with real time kinematic (RTK) global navigation satellite systems (GNSS) (Carbonneau and Dietrich, 2017; Dall'Asta et al., 2017). Following this trend, in October 2018 DJI launched the Phantom 4 RTK SUA system which provides (a) a direct link with a DJI-manufactured differential RTK-GNSS base station, and (b) the recording of raw GNSS trajectory observations for further post-processing; two components that were not included in any previous Phantom models. Up until now there has been no detailed published work of rigorous assessment of the Phantom 4 RTK (P4RTK) system in relation to photogrammetric data acquisition and performance. However, Fraser (2018) recently reported results from the self-calibrating bundle adjustment application to the Phantom 4 Pro (P4P) system investigating different network geometry rules. The study presented here investigates the capabilities of both the P4P and the new P4RTK systems through both laboratory and in-situ assessments. The assessment makes findings regarding the sensors' internal calibration stability and external geometrical accuracy performance using multi-scale photogrammetric network configurations.

\section{METHODOLOGY}

The methodological workflow consisted of two main stages. The first stage involved laboratory and in-situ outdoor field surveys to geometrically calibrate the imaging sensors mounted on-board the P4P and P4RTK SUA using an in-house manufactured $3 \mathrm{D}$ calibration cube with fixed discrete black and white coded targets. This stage performed sensor calibration and subsequent determination of the targets' 3D coordinates by three different approaches: (a) standard self-calibrating bundle adjustment using only the coded targets as image observations, implemented in the photogrammetric software package VMS (Vision Measurement System, VMS (2018); Shortis et al. (1998)); (b) self-calibrating bundle adjustment incorporated into the SfM-photogrammetric pipeline, as implemented in Agisoft Metashape (AM); and (c) self-calibrating damped bundle adjustment performed with the open-source software package DBAT (Damped Bundle Adjustment Toolbox, Börlin et al. (2018)).

All three software packages have adopted the Brown lens distortion model (Brown, 1971). VMS uses the image observations of the coded targets alongside the surveyed targets' 3D coordinates as external constraints for the photogrammetric network solution. In addition to those, AM and DBAT also include tie point observations from the SfM process detected across multiple image stereopairs. The location of coded targets were automatically detected on imagery in AM. Their image coordinates were then used as input observations in both VMS and DBAT. Following computation, a comparable quantitative analysis of the three outputs was conducted. Outputs estimated by the three bundle adjustments, included: a) the camera's interior orientation parameters (IOP) (i.e. focal length (f), principal point location ( $\left.x_{P}, y_{P}\right),\left(K_{1}, K_{2}\right.$, $\left.\mathrm{K}_{3}\right)$ parameters of symmetrical radial lens distortion, and $\left(\mathrm{P}_{1}\right.$, $\mathrm{P}_{2}$ ) parameters or decentring distortion); b) the camera's exterior orientation parameters (EOP); c) the targets' 3D coordinates of the calibration cube; and d) root mean square errors (RMSEs) between surveyed and estimated 3D coordinates of the coded targets.
The second stage involved an in-situ self-calibration assessment with large depth variation in object space and 3D surface model reconstruction (i.e. dense point clouds (DPCs) and DEMs). This stage included quantitative analysis under (a) various imaging network configurations such as standard aerial near-nadir image blocks at different heights with / without the inclusion of oblique imagery, and (b) different GCP configurations of varying number and distribution.

In particular, seven imaging network configurations were designed as follows: 1) nadir imagery at $50 \mathrm{~m}$ flying height above ground level $(50 \mathrm{n})$; 2) nadir imagery at $75 \mathrm{~m}(75 \mathrm{n}) ; 3$ ) nadir and oblique imagery at $50 \mathrm{~m}(50 \mathrm{n} 50 \mathrm{o})$; 4) nadir and oblique imagery at $75 \mathrm{~m}(75 \mathrm{n} 75 \mathrm{o}) ; 5)$ nadir imagery at $50 \mathrm{~m}$ and $75 \mathrm{~m}$ with oblique imagery at $50 \mathrm{~m}(50 \mathrm{n} 75 \mathrm{n} 50 \mathrm{o})$; 6) nadir imagery at $50 \mathrm{~m}$ and $75 \mathrm{~m}(50 \mathrm{n} 75 \mathrm{n})$; 7) a combined image block configuration of all acquired images. Regarding GCP configurations, between four and nine GCPs were incorporated into the SfM-photogrammetric bundle adjustment. DBAT and AM were used for the comparison of sensor calibration estimations and AM was used for 3D surface model reconstruction. Error evaluation at 19 independent check points (ICPs) supported the accuracy assessment between the two DJI systems. Finally, to preliminarily assess the enhanced GNSS capabilities, the previous analysis was also performed using only the P4RTK-generated camera exposure stations without GCP inclusion into the SfM-photogrammetric bundle adjustment. Various parameter settings in AM (e.g. tie point/marker accuracies) were kept identical across the aforementioned tests for both methodological stages.

\section{DJI SUA SYSTEMS}

The P4P and P4RTK SUA are DJI quadcopters, each weighing less than $1.4 \mathrm{~kg}$. Both systems can fly autonomously for up to c. 30 minutes. The P4P SUA is equipped with a single-frequency GNSS receiver and a consumer-grade Micro-Electro Mechanical System-Inertial Measurement Unit (MEMS-IMU) for navigation based on predefined flight paths. Unlike the P4P, the P4RTK carries a multi-frequency GNSS receiver with RTK functionality which enables improved SUA stability and 3D positional accuracy whilst hovering, as stated in DJI P4RTK (2019).

The P4P SUA carries a DJI FC6310 camera with an $8.8 \mathrm{~mm}$ nominal focal length, and a 1" CMOS 20 megapixel sensor with $2.41 \times 2.41 \mu \mathrm{m}$ nominal pixel size. The DJI FC6310 camera creates an image of $5472 \times 3648$ pixels corresponding to $13.2 \times 8.8 \mathrm{~mm}$. The P4RTK is equipped with a DJI FC6310R camera which has a glass lens rather than a plastic one, as fitted on the P4P sensor. The remaining specifications of the P4RTK FC6310R camera are identical to the P4P camera, according to DJI P4RTK (2019). However, the P4RTK only records images in jpg format, whereas the $\mathrm{P} 4 \mathrm{P}$ also stores raw images in DNG format which are not pre-calibrated. The P4RTK can also capture non-calibrated images but only in jpg format, implying that a form of post-processing is carried out within the DJI system when an image is recorded and saved.

It should be noted that the two systems use different DJI control software to define flight and camera settings, named the Go 4 and the GS RTK for the P4P and the P4RTK, respectively. As the P4RTK SUA has only been recently launched, the GS RTK software version is yet to be updated. Therefore, it provides limited control for camera parameterisation set-up, as opposed to the Go 4 software. For example, at the time of image 
acquisition the GS RTK software only allowed for an automatic focus without a description of the captured image size. It is anticipated that future versions of both software will be continually improved, enabling full manual control for settingup all necessary camera parameters prior to SUA flight.

\section{DATA ACQUISITION}

\subsection{Laboratory and in-situ outdoor SUA campaigns}

A first indoor laboratory survey was carried out on $5^{\text {th }}$ December 2018 and included image acquisition with a P4P from 10 camera stations in total, with convergent views of approximately 80 degrees from the centre of the 3D cube (Figure 1a). Inset images in Figure 1a and 1b illustrate the 3D calibration cube when used indoors and outdoors, respectively. In a similar manner, a second indoor lab survey was conducted on 13 ${ }^{\text {th }}$ March 2019 which included image capture with a $\mathrm{P}_{4} \mathrm{RTK}_{2}$ from 13 camera stations. In both surveys the SUA were manually positioned on a stable surface to ensure sharp image capture. Due to the fitted 3-axis gimbal stabilisation, the SUA were manually rotated to capture images at \pm 90 degree roll angles. Camera settings for the P4P and $\mathrm{P}_{4} \mathrm{RTK}_{2}$ laboratory campaigns are reported in Table 1.

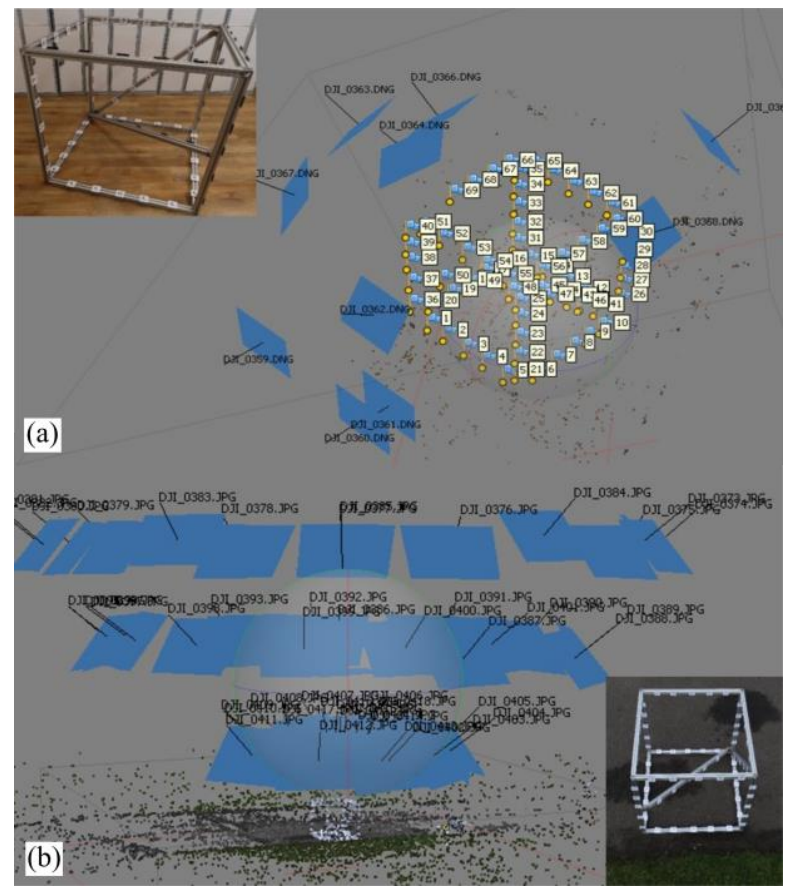

Figure 1. (a) Laboratory and (b) outdoor field surveys of the first methodological stage using the $\mathrm{P} 4 \mathrm{P}$ and $\mathrm{P}_{4} \mathrm{RTK}_{1}$.

Two outdoor flights were conducted on $12^{\text {th }}$ December 2018 with image capture following a circular pattern, as seen in Figure $1 \mathrm{~b}$, with an average $7 \mathrm{~m}$ height variation above the ground. Both flights were operated in manual mode and imagery was captured while the SUA were hovering to minimise image blur. The camera settings, as defined prior to SUA flights, are listed in Table 1. The GS RTK software did not allow to manually set a fixed $1 / 1000$ shutter speed, as adopted on the P4P settings. Moreover, due to the GS RTK software limitations (see Section 3), the $\mathrm{P}_{\mathrm{RTKK}}$ captured images with different image heights to the P4P imagery, as detailed in Table 1.
38 and 49 images were acquired in total with the $\mathrm{P} 4 \mathrm{P}$ and $\mathrm{P}_{4} \mathrm{RTK}_{1}$, respectively. It should be noted that, because of software differences, there was no option to share the same predefined flight plan between the two systems, hence the slightly different number of images and configurations. 67 coded targets on the calibration cube, used for both indoor and outdoor tests, were pre-surveyed using a total station to deliver mm-level 3D coordinate accuracy in a local coordinate system. An a priori standard deviation of $5 \mathrm{~mm}$ was assigned to coded targets, which corresponds to marker accuracy in the SfM-photogrammetric bundle adjustment in AM.

At this point, it should be noted that the $\mathrm{P}_{4} \mathrm{RTK}_{1}$ system used on $12^{\text {th }}$ December 2018, was loaned by Heliguy, a DJI retail company (Heliguy, 2019), for several days. $\mathrm{P}_{4} \mathrm{RTK}_{2}$, used for the laboratory survey conducted on $13^{\text {th }}$ March 2019, was a different system, which was purchased by Newcastle University that month.

\begin{tabular}{|l|c|c|c|}
\hline Campaigns & Laboratory & Outdoors & $\begin{array}{c}\text { Wards Hill } \\
\text { Quarry }\end{array}$ \\
\hline Aperture & $\mathrm{f} / 2.8$ & $\mathrm{f} / 2.8$ & $\mathrm{f} / 2.8$ \\
Shutter & $1 / 40$ & $1 / 1000$ & $1 / 1000$ \\
speed & $(1 / 80)$ & $(1 / 640)$ & $400(200)$ \\
ISO & 100 & 200 & $5472 \times 3648$ \\
Image size & $5472 \times 3648$ & $5472 \times 3648^{* *}$ \\
Aircraft & $(5472 \times 3078)^{*}$ & $(5472 \times 3078)^{* * *}$ & $5472 \times 1 \mathrm{~m} / \mathrm{s}$ \\
speed & $0 \mathrm{~m} / \mathrm{s}$ & $0 \mathrm{~m} / \mathrm{s}$ & $(3 \mathrm{~m} / \mathrm{s})$ \\
\hline
\end{tabular}

Refers to P4RTK 2 used on $13^{\text {th }}$ March 2019

${ }^{* *}$ Refers to P4RTK 1 used in December 2018

Table 1. Details of data acquired with the P4P and P4RTK SUA at all campaigns in the two methodological stages. Differences, shown in brackets, correspond to the P4RTK SUA.

\subsection{SUA campaign at Wards Hill quarry}

An in-situ self-calibration SUA campaign (see second stage of the methodology) was conducted on $13^{\text {th }}$ December 2018 at Wards Hill Quarry, Morpeth, UK (Figure 2a). The quarry is now abandoned but it was actively producing limestone in the 1920 s. The site is private, consisting primarily of grassland used for livestock grazing with occasional trees. Due to the considerable ground lowering where the limestone was quarried, the site provides a suitable area to investigate the effect of image scale variations and surface gradients on SfM-photogrammetric outputs.

To ensure that SfM-photogrammetric products from both SUA were georeferenced into a common fixed reference frame (Ordnance Survey Great Britain 1936, OSGB36), 28 targets were surveyed using GNSS rapid static mode with three-minute observations per point (Figure $2 \mathrm{~b}$ ). An average 3D relative accuracy of $0.003 \mathrm{~m}$ was estimated after post-processing with GNSS observations from OS Net station MORO.

337 and 575 images were collected in total using the P4P and $\mathrm{P}_{4} \mathrm{RTK}_{1}$, respectively. This included nadir images from $50 \mathrm{~m}$ and $75 \mathrm{~m}$ flying heights, as well as oblique images within the range of 45 degrees to 75 degrees pitch angle (see combined imaging configuration; Figure 2c). For nadir image capture both systems were operated in automatic mode, whereas oblique images were acquired in manual mode. Because of the GS RTK software early version limitations, and in contrast to the P4P, the $\mathrm{P}_{4} \mathrm{RTK}_{1}$ SUA did not hover to capture images when flying 
in automatic mode. For this reason the $\mathrm{P} \mathrm{RTK}_{1}$ was flying with a minimum constant speed of $3 \mathrm{~m} / \mathrm{s}$ (Table 1) to minimise motion blur. $80 \%$ forward and $80 \%$ lateral overlap were predefined in both the Go 4 and GS RTK software.

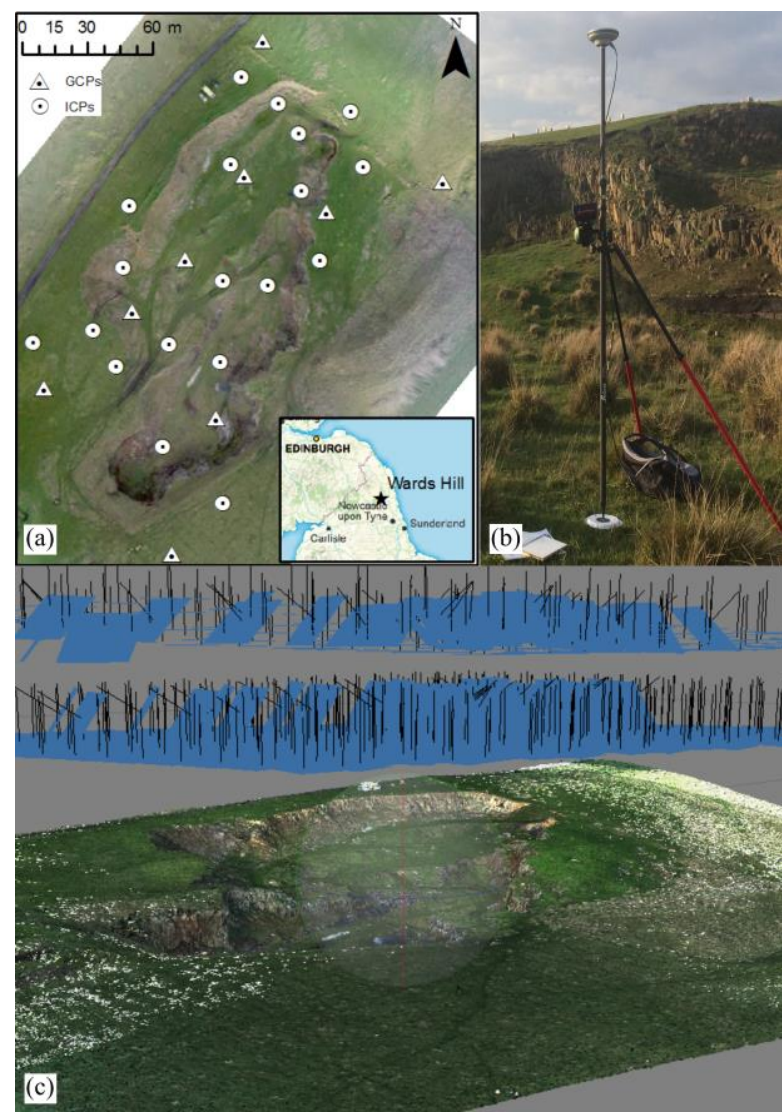

Figure 2. (a) Wards Hill Quarry overview (P4P-generated orthomosaic), (b) GNSS set up over a circular target with partial view of the quarry in the background, and (c) DPC generated from $\mathrm{P}_{4 R T K} \mathrm{~K}_{1}$ imagery with mixed range block geometry (captured at $50 \mathrm{~m}$ and $75 \mathrm{~m}$ above ground level, including oblique imagery)

\section{RESULTS AND DISCUSSION}

\subsection{Laboratory and in-situ outdoor SUA campaigns}

Table 2 presents provisional results for estimated values of the focal length and principal point location of the P4P camera from the indoor laboratory calibration. It also shows planimetric and vertical RMSEs at 41 check points. The remaining 26 targets of the 3D cube, seen in Figure 1a, served as external constraints in the bundle adjustment. According to the DBAT solution, a maximum $24 \mu \mathrm{m}$ distortion (including radial and decentring distortion) was estimated at the half-diagonal of the P4P image radius (i.e. $7 \mathrm{~mm}$ radial distance). An average optical-ray angle generated from the 1700 tie points was 12 degrees, whereas the average optical-ray obtained from the coded targets was 70 degrees. Images acquired with a wider baseline and a better convergent angle would generate more tie points at the corners of each image, in turn strengthening the photogrammetric network solutions.

\begin{tabular}{|l|r|r|}
\hline & AM & \multicolumn{2}{|c|}{ DBAT } \\
\hline f [mm] & 8.850 & 8.853 \\
XP [mm] & 0.016 & 0.017 \\
yP [mm] & -0.024 & -0.021 \\
RMSE XY [mm] & 1.179 & 1.234 \\
RMSE Z [mm] & 0.527 & 0.551 \\
\hline
\end{tabular}

Table 2. P4P calibration outputs obtained with AM and DBAT software from the lab field survey carried out on $5^{\text {th }}$ December 2018 using nine images.

\begin{tabular}{|l|r|r|}
\hline & \multicolumn{1}{|c|}{ VMS } & \multicolumn{2}{|c|}{ DBAT } \\
\hline & \multicolumn{2}{|c|}{ Laboratory $-13^{\text {th }}$ March 2019 } \\
\hline f [mm] & 9.183 & 9.187 \\
XP [mm] & -0.007 & -0.001 \\
yP [mm] & -0.065 & -0.038 \\
RMSE XY [mm] & 2.630 & 1.774 \\
RMSE Z [mm] & \multicolumn{2}{|c|}{1.469} \\
\hline & Outdoors $-12^{\text {th }}$ December 2018 \\
\hline f [mm] & 9.266 & 9.540 \\
XP [mm] & 0.044 & 0.000 \\
yP [mm] & -0.055 & 0.000 \\
RMSE XY [mm] & 1.823 & 2.518 \\
RMSE Z [mm] & 0.698 & 0.920 \\
\hline
\end{tabular}

${ }^{*}$ Refers to $\mathrm{P} 4 \mathrm{RTK}_{2}$

${ }^{* *}$ Refers to P4RTK

Table 3. P4RTK calibration outputs obtained with VMS and DBAT software from the laboratory and in-situ outdoor field surveys. Note that two P4RTK systems were used, as explained Section 4.1.

Provisional P4P results from the in-situ outdoor field survey reported a maximum distortion of $46 \mu \mathrm{m}$ at the half-diagonal. Maximum distortion differences of $8 \mu \mathrm{m}$ and $9 \mu \mathrm{m}$ between the VMS-AM and VMS-DBAT approaches were produced at the outer corners of the image, respectively. All outdoor survey approaches delivered planimetric and vertical RMSEs of the same mm-magnitude as RMSEs at check points of the indoor survey (Table 2). Regarding outdoor survey, VMS and DBAT estimated the values of the focal length and principal point location with maximum differences of $10 \mu \mathrm{m}$ and $5 \mu \mathrm{m}$, respectively. Such discrepancies could be attributed to the two types of bundle adjustments adopted; a standard photogrammetric approach in VMS versus SfM-based in DBAT.

Possibly due to the aforementioned reason, a significant difference of $55 \mu \mathrm{m}$ was calculated at the principal point $\mathrm{yP}_{\mathrm{P}}$ coordinate between VMS and DBAT for the P4RTK 1 outdoor survey, as seen in Table 3. Variations in focal length estimated values between the two surveys can be attributed to two factors: a) two different P4RTK systems were used (see Section 4.1) and b) different focus was set up between the indoor and outdoor experiment.

Regarding $\mathrm{P}_{4} \mathrm{RTK}_{2}$ distortion estimation, a $42 \mu \mathrm{m}$ maximum distortion was calculated at the outer corners of the $\mathrm{P}_{4} \mathrm{RTK}_{2}$ image from the indoor laboratory survey. From the outdoor survey, a $67 \mu \mathrm{m}$ maximum distortion was estimated at the outer corners of the $\mathrm{P} \mathrm{RTK}_{1}$ image. It should be noted that for indoor and outdoor tests $\mathrm{P}_{4} \mathrm{RTK}_{2}$ and $\mathrm{P}_{4} \mathrm{RTK}_{1}$ imagery respectively had a different image format size to the P4P imagery (see Table 1). The $\mathrm{P}_{4} \mathrm{RTK}_{2}$ and $\mathrm{P}_{4} \mathrm{RTK}_{1}$ captured images with $13.8 \times 7.8 \mathrm{~mm}$ width and height of a $2.52 \times 2.52 \mu \mathrm{m}$ pixel size. Moreover, at all calibration tests, a high correlation of over $95 \%$ 
was observed between $\mathrm{K}_{1}$ and $\mathrm{K}_{3}$ radial distortion coefficients. This finding was expected, as $\mathrm{K}_{1}$ is considered the most critical among all coefficients, especially in the case of compact digital cameras (James and Robson, 2014; Carbonneau and Dietrich, 2017). However, all three coefficients are considered in this calibration analysis to allow comparison with a previous study (Fraser, 2018).

During the ongoing analysis, special consideration is being given to reducing the magnitude of the standard deviations of the estimated IOP values. As Fraser (2018) reports, precision at the $\mu \mathrm{m}$ level is indicative of strong recovery of the estimated IOP values, improving the faithfulness of the photogrammetric calibration output. It should be highlighted that the presented preliminary distortion values were only estimated for the pre-calibrated $\mathrm{P} 4 \mathrm{P}$ and $\mathrm{P}_{4} \mathrm{RTK}_{1}$ and $\mathrm{P}_{4} \mathrm{RTK}_{2}$ imagery. As described in Section 3, DJI software applies a pre-correction to the raw captured images and converts them into jpg format. Ongoing work is evaluating the degree of distortion that has been corrected by DJI and examines whether this can be further minimised, essentially through a secondary calibration.

\subsection{SUA campaign at Wards Hill quarry}

Planimetric and vertical RMSEs at 19 ICPs (Figure 2a) for the seven imaging configurations are shown in Figure 3 , as calculated for both P4P and $\mathrm{P}_{4} \mathrm{RTK}_{1}$ systems. These RMSEs were estimated when four GCPs were incorporated into the selfcalibrating bundle adjustment in AM as external constraints. Among all P4P solutions, the highest RMSEs were observed in the 50n imaging configuration, which is not the case for the $\mathrm{P}_{4} \mathrm{RTK}_{1}$ results. Interestingly, smaller 2D RMSE values were estimated at $75 \mathrm{n}$ rather than the combined solution for the $\mathrm{P} 4 \mathrm{P}$ system (Figure 3a). Nonetheless, the inclusion of oblique imagery considerably improved the level of $\mathrm{P} 4 \mathrm{P}$ vertical accuracies at ICPs (Figure 3b). When comparing the two systems, the $\mathrm{P}_{4 \mathrm{RTK}}$ provided a better consistency, as smaller variations of RMSEs were observed across all configurations, both in plan and elevation, and both with and without the inclusion of oblique images (Figure 3).

Across all the configurations shown in Figure $3 a$, the 50n50o delivered the smallest 2D RMSE value for the P4P system, equal to $13.6 \mathrm{~mm}, 1.7 \mathrm{~mm}$ different from the RMSE value of the combined solution. Whereas, the minimum vertical $\mathrm{P} 4 \mathrm{P}$ RMSE magnitude was observed at the combined solution, corresponding to $28.7 \mathrm{~mm}$. Regarding the $\mathrm{P}_{4} \mathrm{RTK}_{1}$ results, the best planimetric accuracy was achieved by the $50 \mathrm{n} 75 \mathrm{n}$ configuration with a $14.2 \mathrm{~mm}$ RMSE, $1.5 \mathrm{~mm}$ different from the RMSE value of the combined solution. A $28.8 \mathrm{~mm}$ minimum vertical RMSE was calculated at the $75 \mathrm{n} 75 \mathrm{o}$ imaging configuration.

Given that a $16 \mathrm{~mm}$ ground sampling distance (GSD) was estimated for both $\mathrm{P} 4 \mathrm{P}$ and $\mathrm{P}_{4} \mathrm{RTK}_{1}$, the aforementioned planimetric errors correspond to less than $1 \times$ GSD, and agree with results from previous studies. For instance, Chiabrando and Losè (2017) applied a SfM-photogrammetry pipeline with $\mathrm{P} 4 \mathrm{P}$ imagery over a historic building using a mixed block of nadir and circular oblique configurations. They calculated a $12.2 \mathrm{~mm}$ 2D RMSE and a $17 \mathrm{~mm}$ vertical RMSE when comparing the coordinates against GNSS / total station observations (although the estimated GSD was not stated). However, it should be noted that their output values were estimated using only eight ICPs (Chiabrando and Losè, 2017). (a) Planimetric

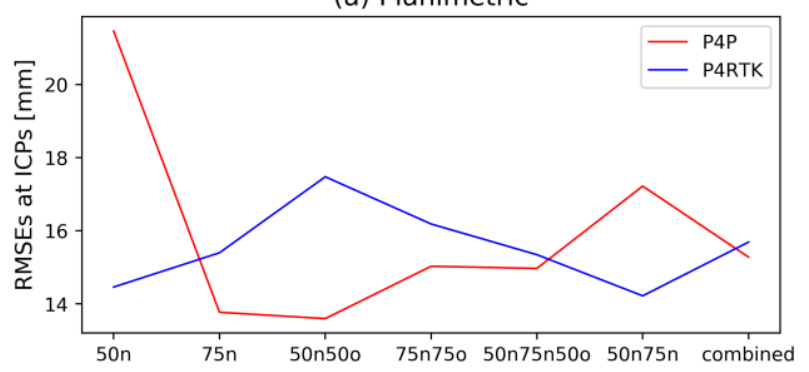

(b) Vertical

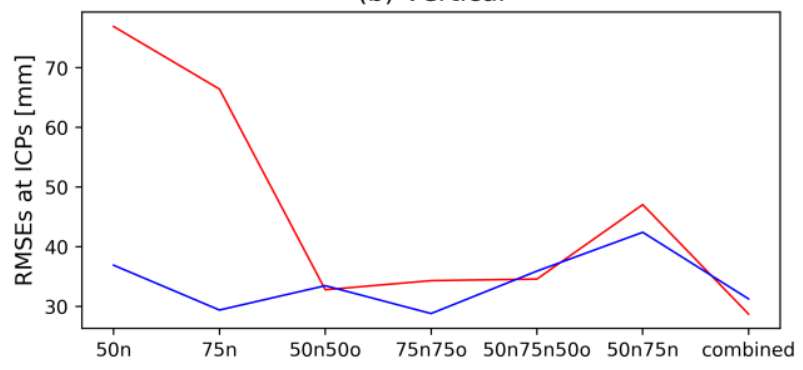

Figure 3. P4P and $\mathrm{P}_{\mathrm{RTK}}$ (a) planimetric and (b) vertical RMSEs estimated at 19 ICPs with a SfM-photogrammetric bundle adjustment in AM using four GCPs under various imaging configurations.

In the analysis here, a $1.8 \times$ GSD vertical accuracy (i.e. approximately $29 \mathrm{~mm}$ vertical RMSE) was delivered from both P4P and P4RTK 1 SUA. It should be noted that during the SUA flights, lighting conditions were continuously varying (from strong shadow to winter sun glare), therefore imagery was illuminated differently, as depicted in Figure 2c. Such illumination differences could have adversely affected the SfM tie point detection pipeline on overlapping images (Eltner et al., 2016), which in turn potentially degraded the vertical accuracy level.

To estimate the magnitude of $3 \mathrm{D}$ error in relation to the flying height, the RMSE values of the combined configuration were transformed into relative error ratios. A ratio of 1:1900 was estimated for both $\mathrm{P} 4 \mathrm{P}$ and $\mathrm{P}_{4} \mathrm{RTK}_{1}$ SUA under a multi-scale photogrammetric block configuration. This agrees with reported relative ratios obtained with rotor-wing SUA in previous studies (e.g. Eltner et al. (2015)).

The inclusion of additional GCPs was not found to significantly improve the results of the presented analysis. The terrain depth variations, alongside the varying camera station heights, resulted in a multi-scale photogrammetric network, providing low RMSE values. However, when only camera stations obtained with the $\mathrm{P}_{4} \mathrm{RTK}_{1}$ in the $75 \mathrm{n}$ configuration, were utilised as external constraints in the AM SfM-photogrammetry pipeline (i.e. zero GCPs), the absolute accuracy reduced significantly. $1.0 \mathrm{~m}$ planimetric and $2.2 \mathrm{~m}$ vertical RMSEs were estimated at ICPs, with a systematic bias mainly in the Northing coordinate (RMSE Easting equal to $0.031 \mathrm{~m}$ and $\mathrm{RMSE}_{\text {Northing }}$ equal to $0.993 \mathrm{~m}$ ).

Moreover, a bowl-shape vertical distortion was generated, as shown in Figure 4a. This bias was effectively removed (Figure $4 b$ ) with the inclusion of four GCPs (established at the corners of the study site) into the AM SfM-photogrammetric pipeline. Therefore, a minimum of a few GCPs is necessary to remove 
such a bowl-shape effect, as reported in previous studies (James and Robson, 2014; Carbonneau and Dietrich, 2017). However, even with GCPs as external constraints, variances of higher magnitude than the estimated vertical RMSEs (i.e. $29 \mathrm{~mm}$ ), were observed at the outer corners of the study site (Figure 4b). This can be caused partly due to the single-scale image photogrammetric block ( $75 \mathrm{~m}$ nadir imagery in Figure $4 \mathrm{~b}$ ). Also, as Fraser (2018) reported, biases in point positions cannot be entirely removed, even with GCP inclusion into the SfMphotogrammetric bundle adjustment, and can often have magnitudes greater than the estimated standard deviations.

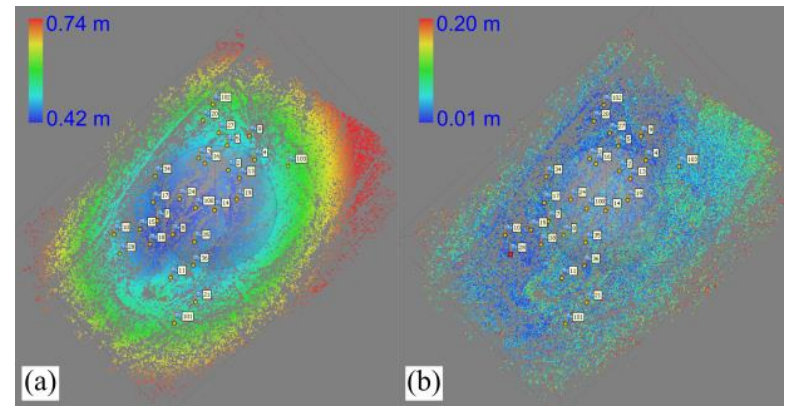

Figure 4. Plan view of estimated variances at tie points from the $\mathrm{P}_{4} \mathrm{RTK}_{1}$ SfM-photogrammetric bundle adjustment in AM with nadir imagery at $75 \mathrm{~m}$ and (a) zero GCPs, and (b) four GCPs.

Note the different vertical colour scales.

\section{CONCLUSIONS AND FUTURE WORK}

This paper has presented preliminary investigations of the DJI Phantom 4 Pro and Phantom 4 RTK SUA systems in relation to photogrammetric data acquisition. The analysis includes laboratory and in-situ accuracy assessments obtained with selfcalibrating bundle adjustments from VMS, Agisoft Metashape and DBAT software over various imaging block configurations.

Regarding the internal geometry of the two systems, provisional results have indicated that the estimated maximum lens distortion is in the region of $24 \mu \mathrm{m}$ to $67 \mu \mathrm{m}$. This preliminary estimation refers to the pre-calibrated by DJI P4P and P4RTK imagery. Regarding the external geometric accuracy, results have shown that both Phantom DJI systems can deliver planimetric and vertical absolute accuracies of $14 \mathrm{~mm}$ and $29 \mathrm{~mm}$ at ICPs respectively, corresponding to a relative precision of 1:1900. This can be achieved with an imaging network configuration comprising mixed height range and nadir/oblique capture. The terrain depth variation has also contributed to achieving such accuracy levels. As a result, the inclusion of a few GCPs (e.g. four at the outer corners of the study site) are adequate to remove significant positional distortions and strengthen the self-calibrating bundle adjustment. The presented analysis was based on a greater than standard $60 \%$ forward and $40 \%$ lateral image overlap, providing high redundancy.

Ongoing analysis is investigating the consistency of the cameras' IOP values, estimated with the various bundle adjustment solutions from laboratory and in-situ surveys for both systems. In particular, the computed correlations between the focal length and the cameras' EOP is currently being analysed. Attention is also being given on the magnitude of the estimated standard deviations of both IOPs and EOPs. Ways to strengthen the bundle adjustment solutions, thereby improving their internal precision, are under investigation. Further evaluation on estimating the lens distortion of the raw $\mathrm{P} 4 \mathrm{P}$ and P4RTK imagery is also scheduled.

Future work includes an additional validation of the RMSEs at ICPs independently from the Agisoft Metashape estimations. Such analysis will compare the ICP 3D coordinates, manually extracted from the reconstructed DPC and/or orthomosaic in a different software package against the surveyed ICP 3D coordinates. Importantly, regarding the RTK capabilities of the Phantom 4 RTK SUA, further post-processing of its trajectory in conjunction with an OS Net base station is also scheduled. This can potentially improve the metre-level accuracy of camera exposure station positions. Error analysis of the cameras' IOP/EOP and computation of RMSEs at ICPs after the RTK post-processing is also planned.

Ultimately, findings from comprehensive accuracy assessments can demonstrate the capabilities and metric performance of these new and popular off-the-shelf DJI SUA systems. Such error analysis can provide non-experts with a better understanding of associated uncertainties and measurement precision levels, thereby supporting the design of pre-flight photogrammetric data acquisition for a wide range of applications.

\section{ACKNOWLEDGEMENTS}

This research was supported by UKCRIC - UK Collaboratorium for Research in Infrastructure \& Cities: Newcastle Laboratories (EPSRC award EP/R010102/1). The authors would like to thank Heliguy for the loan of the Phantom 4 RTK (P4RTK $)_{1}$ system on $12^{\text {th }}$ and $13^{\text {th }}$ December 2018.

\section{REFERENCES}

Börlin, N., Murtiyoso, A., Grussenmeyer, P., Menna, F., Nocerino, E. 2018. Modular bundle adjustment for photogrammetric computations. Int. Arch. Photogramm. Remote Sens. Spatial Inf. Sci., XLII-2, 133-140, doi.org/10.5194/isprs-archives-XLII-2-133-2018.

Brown, D. C. 1971. Close-range camera calibration. Photogrammetric Engineering, 37(8), 855-866.

CAP 393 2019. The Air Navigation Order 2016 and Regulations. Civil Aviation Authority, UK.

Carbonneau, P. E. and Dietrich, J. T. 2017. Cost-effective nonmetric photogrammetry from consumer-grade sUAS: implications for direct georeferencing of structure from motion photogrammetry. Earth Surface Processes and Landforms, 42(3), 473-486, doi.org/10.1002/esp.4012.

Casella, E., Collin, A., Harris, D., Ferse, S., Bejarano, S., Parravicini, V., Hench, J. L., Rovere, A. 2017. Mapping coral reefs using consumer-grade drones and structure from motion photogrammetry techniques. Coral Reefs, 36(1), 269-275, doi.org/10.1007/s00338-016-1522-0.

Chiabrando, F. and Losè, L. T. 2017. Performance evaluation of COTS UAV for architectural heritage documentation. A test on S.Giuliano Chapel in Savigliano (CN) - Italy. Int. Arch. Photogramm. Remote Sens. Spatial Inf. Sci., 42, 77-84, doi.org/10.5194/isprs-archives-XLII-2-W6-77-2017.

Dall'Asta, E., Forlani, G., Roncella, R., Santise, M., Diotri, F., Morra di Cella, U. 2017. Unmanned Aerial Systems and DSM 
matching for rock glacier monitoring. ISPRS Journal of Photogrammetry and Remote Sensing, 127(1), doi.org/10.1016/j.isprsjprs.2016.10.003.

DJI, 2019. DJI drone manufacturer (Phantom Series). https://www.dji.com/uk/support/product?site=brandsite \&from= footer $\left(15^{\text {th }}\right.$ January 2019$)$.

DJI P4RTK, 2019. P4RTK system specifications. https://www.dji.com/uk/phantom-4-rtk/info\#specs $\quad\left(1^{\text {st }}\right.$ March 2019).

Eltner, A., Baumgart, P., Maas, H. G., Faust, D. 2015. Multitemporal UAV data for automatic measurement of rill and interrill erosion on loess soil. Earth Surface Processes and Landforms, 40(6), 741-755, doi.org/10.1002/esp.3673.

Eltner, A., Kaiser, A., Castillo, C., Rock, G., Neugirg, F., Abellán, A. 2016. Image-based surface reconstruction in geomorphometry-merits, limits and developments. Earth Surface Dynamics, 4(2), 359-389, doi.org/10.5194/esurf-4-3592016.

Ewertowski, M. W., Tomczyk, A. M., Evans, D. J. A., Roberts, D. H., Ewertowski, W. 2019. Operational Framework for Rapid, Very-high Resolution Mapping of Glacial Geomorphology Using Low-cost Unmanned Aerial Vehicles and Structure-from-Motion Approach. Remote Sensing, 11(1), 65, doi.org/10.3390/rs11010065.

Fraser, C., 2018. Oral presentation at ISPRS Technical Comm. II Symposium 2018, Riva del Garda, Italy, 3 - 7 June 2018 entitled: Camera Calibration Considerations for UAV Photogrammetry.

http://www.isprs.org/tc2-symposium2018/images/ISPRS-

Invited-Fraser.pdf (15 $5^{\text {th }}$ November 2018).

Grayson, B., Penna, N. T., Mills, J. P., Grant, D. S. 2018. GPS precise point positioning for UAV photogrammetry. The Photogrammetric Record, 33(164), 427-447, doi.org/10.1111/phor.12259.

Heliguy, 2019. Retail brand presence of the company Colena Ltd including DJI SUAs. www.heliguy.com $\left(15^{\text {th }}\right.$ December 2018).

Hese, S.,Behrendt and F. 2017. Multiseasonal tree crown structure mapping with point clouds from OTS quadrocopter systems. Int. Arch. Photogramm. Remote Sens. Spatial Inf. Sci., 42, 141-143, doi.org/10.5194/isprs-archives-XLII-2-W6-1412017.

James, M. R. and Robson, S. 2014. Mitigating systematic error in topographic models derived from UAV and ground-based image networks. Earth Surface Processes and Landforms, 39(10), 1413-1420, doi.org/10.1002/esp.3609.

Malambo, L., Popescu, S. C., Murray, S. C., Putman, E., Pugh, N. A., Horne, D. W., Richardson, G., Sheridan, R., Rooney, W. L., Avant, R., Vidrine, M., McCutchen, B., Baltensperger, D., Bishop, M. 2018. Multitemporal field-based plant height estimation using 3D point clouds generated from small unmanned aerial systems high-resolution imagery. International Journal of Applied Earth Observation and Geoinformation, 64, 31-42, doi.org/10.1016/j.jag.2017.08.014.
Metashape, 2018. Agisoft Metashape photogrammetric SfMMVS commercial software version 1.5.0. www.agisoft.com (15 $5^{\text {th }}$ January 2019).

Peppa, M. V., Mills, J. P., Moore, P., Miller, P. E., Chambers, J. E. 2018. Automated co-registration and calibration in SfM photogrammetry for landslide change detection. Earth Surface Processes and Landforms, doi.org/10.1002/esp.4502.

Shortis, M. R. and Robson, S.,Beyer, H. A. 1998. Principal point behaviour and calibration parameter models for kodak DCS cameras. Photogrammetric Record, 16(92), 165-186.

Toth, C. and Jóźków, G. 2016. Remote sensing platforms and sensors: A survey. ISPRS Journal of Photogrammetry and Remote Sensing, 115, 22-36, doi.org/10.1016/j.isprsjprs.2015.10.004.

VMS, 2018. Vision Measurement System, Photogrammetric software package. www.geomsoft.com $\left(15^{\text {th }}\right.$ November 2018).

Woodget, A. S., Carbonneau, P. E., Visser, F., Maddock, I. P. 2015. Quantifying submerged fluvial topography using hyperspatial resolution UAS imagery and structure from motion photogrammetry. Earth Surface Processes and Landforms, 40(1), 47-64, doi.org/10.1002/esp.3613. 